\section{E-017 IMPACT OF THE DOME OF ANEURYSM ORIENTATION IN RELATION TO GRAVITY ON THE OUTCOME AFTER SUB- ARACHNOID HEMORRHAGE: A SINGLE CENTER CASE SERIES}

G Ramaiah*, I Sheikh, R Burgess, S Zaidi. Neurology, University of Toledo, Toledo, $\mathrm{OH}$

\subsection{6/neurintsurg-2019-SNIS.92}

Introduction Aneurysmal subarachnoid hemorrhage is a neurological emergency that is associated with significant morbidity and mortality. There are multiple factors both modifiable and non-modifiable that contribute to the rupture of an aneurysm. Laboratory experiment has shown that orientation of the dome of aneurysm downwards, parallel to the force of gravity, has a higher risk of thrombosis and rupture because of turbulence. ${ }^{1}$ Another experiment revealed that red blood cells tend to settle in aneurysms that are oriented downwards. ${ }^{2}$ This could trigger thrombus formation and eventual rupture. We aim to study the effect of the orientation of dome of the aneurysm on the presenting severity and outcome of the subarachnoid hemorrhage.

Methods A retrospective review of medical records of 38 subjects (with a total of 41 saccular aneurysms) who presented with aneurysmal subarachnoid hemorrhage between 2012 and 2018 was performed. The information collected for the study included the age of the patient, maximal dimension of aneurysm, orientation of dome of an aneurysm in relation to gravity, Hunt and Hess scale, Fisher scale, modified Rankin scale at discharge, modality of treatment (endovascular coiling or surgical clipping), history of hypertension, history of hyperlipidemia, history of diabetes, history of antiplatelet and anticoagulant medication usage prior to hemorrhage, history of smoking and family history of aneurysm.

Results 41 Aneurysms in 38 subjects were divided in to two groups based on the orientation of the dome of the aneurysm in relation to gravity. 20 aneurysms $(48.78 \%)$ were oriented towards the force gravity with dome of the aneurysm in the direction of the force of gravity. There was no statistical

\begin{tabular}{|c|c|c|}
\hline $\begin{array}{l}\text { Orientation of the dome of } \\
\text { aneurysm in relation to gravity }\end{array}$ & $\begin{array}{l}\text { Dome of aneurysm } \\
\text { oriented towards the } \\
\text { force of gravity } \\
\text { (number = 20). }\end{array}$ & $\begin{array}{l}\text { Dome of aneurysm } \\
\text { not oriented towards } \\
\text { the force of gravity } \\
\text { (number = 21). }\end{array}$ \\
\hline Female Gender & 16 & 15 \\
\hline Anterior Circulation & 19 & 14 \\
\hline Maximum Dimension in mm (mean) & 5.6 & 5.3 \\
\hline Age in years (mean) & 60.25 & 57.38 \\
\hline History of Hypertension & 15 & 13 \\
\hline History of Diabetes Mellitus & 3 & 2 \\
\hline History of Hyperlipidemia & 8 & 9 \\
\hline History of Antiplatelet use & 3 & 5 \\
\hline History of Anticoagulant use & 1 & 0 \\
\hline Family History of Aneurysm & 2 & 2 \\
\hline History of Smoking & 12 & 16 \\
\hline $\begin{array}{l}\text { Hunt and Hess Scale on admission } \\
\text { (mean) }\end{array}$ & 3.05 & 3.15 \\
\hline Fisher Scale on admission (mean) & 2.9 & 3.52 \\
\hline Endovascular Coiling & 17 & 15 \\
\hline $\begin{array}{l}\text { Modified Rankin Scale on discharge } \\
\text { (mean) }\end{array}$ & 3.15 & 3.28 \\
\hline
\end{tabular}

difference in the severity of the subarachnoid hemorrhage (Hunt and Hess scale, Fisher grading scale) and the outcome after subarachnoid hemorrhage (modified Rankin Scale for neurologic disability) between the two groups.

Conclusion Of the aneurysms that were oriented towards the force of gravity, 19 aneurysms (95\%) were present in the anterior circulation. Application of this concept to a larger prospective database that includes both unruptured and ruptured aneurysms may show a statistical significant difference in the outcome. Such studies could serve to identify the orientation of the dome of an aneurysm in relationship to gravity as an important factor in contributing to the rupture of a saccular aneurysm.

\section{REFERENCES}

1. Madrazo I, et al. Effect of position with respect to gravitational force on the hydrodynamics of an experimental model of saccular aneurysm. PMID: 2103697

2. Chodzyński KJ, et al. Does the gravity orientation of saccular aneurysms influence hemodynamics? An experimental study with and without flow diverter stent. PMID: 27810105

Disclosures G. Ramaiah: None. I. Sheikh: None. R. Burgess: None. S. Zaidi: None.

\section{E-018 TRANSCIRCULATION APPROACH IN COMPLEX ENDOVASCULAR PROCEDURES: A MULTICENTER STUDY}

1J Roa*, ${ }^{2} \mathrm{G}$ Dabus, ${ }^{3} \mathrm{~A}$ Maud, ${ }^{4} \mathrm{M}$ Martinez-Galdamez, ${ }^{5} \mathrm{D}$ Paez-Granda, ${ }^{6} \mathrm{~V}$ Kalousek, ${ }^{7} \mathrm{~A}$ Mowla, ${ }^{7} \mathrm{~V}$ Szeder, ${ }^{8} \mathrm{P}$ Jabbour, ${ }^{9} \mathrm{~S}$ Ortega-Gutierrez, ${ }^{10} \mathrm{D}$ Hasan, ${ }^{9} \mathrm{E}$ Samaniego. ${ }^{1}$ Neurology and Neurosurgery, University of lowa Hospitals and Clinics, lowa City, IA; ${ }^{2}$ Neurology, Miami Cardiac and Vascular Institute, Miami, FL; ${ }^{3}$ Neurology, Texas Tech University Health Sciences Center El Paso, El Paso, TX; ${ }^{4}$ Neurology, Fundación Jiménez Diaz University Hospital, Madrid, Spain; ${ }^{5}$ Neurology, Virgen de la Arrixaca University Hospital, Murcia, Spain; ${ }^{6}$ Neurology, University Clinical Hospital Center 'Sestre Milosrdnice', Zagreb, Croatia; 'Diagnostic and Interventional Radiology, University of California Los Angeles, Los Angeles, $C A ;{ }^{8}$ Neurosurgery, Thomas Jefferson University Hospitals, Philadelphia, PA; ${ }^{9}$ Neurology, Neurosurgery and Radiology, University of lowa Hospitals and Clinics, lowa City, IA; ${ }^{10}$ Neurosurgery, University of lowa Hospitals and Clinics, lowa City, IA

\subsection{6/neurintsurg-2019-SNIS.93}

Background Unfavorable anatomy can preclude traditional anterograde endovascular intervention through the parent vessel. Transcirculation approaches provide alternative pathways for successful treatment of these complex cases.

Methods Eight centers provided retrospective data on patients who underwent transcirculation procedures, including embolization of intracranial aneurysms (IAs), dural arteriovenous fistulas (dAVFs) and arteriovenous malformations (AVMs), and thrombectomy of acute ischemic strokes (AIS). Procedural complications, clinical and radiological outcomes were assessed after intervention and last available follow-up.

Results A total of 43 patients were treated using endovascular transcirculation approach: 24 IAs, 13 AIS, 3 AVMs and 3 dAVFs. Mean age was $56.9 \pm 15.3$ years (range 18-82 years), and 24 (55.8\%) were women. Most IAs (19/24, 79.2\%) presented unruptured and were treated electively. 3 AVMs and 2 dAVFs presented ruptured. The most common indication for transcirculation approach was occlusion of the parent artery (21 patients, 48.8\%). The posterior communicating artery (PCOM) was crossed in $20(46.5 \%)$ cases (10 anterior-to-posterior, 10 posterior-to-anterior), anterior communicating artery (ACOM) in 17 cases, and vertebral artery (VA) in 2 cases. In four cases, combined approaches were used (3 ACOM rightto-left and viceversa, one double transcirculation ACOM/ 